\title{
Effective Theranostic Cyanine for Imaging of Amyloid Species in Vivo and Cognitive Improvements in Mouse Model
}

\author{
Yinhui Li, ${ }^{\dagger, \S, \|}$ Chen Chen, ${ }^{\dagger, \ddagger} \|$ Di Xu, ${ }^{\dagger, \|}$ Chung-Yan Poon, ${ }^{\dagger}$ See-Lok Ho, ${ }^{\dagger}$ Rui Zheng, ${ }^{\ddagger}$ Qiong Liu, \\ Guoli Song, ${ }^{*}+$ Hung-Wing Li, ${ }^{*} \dagger$ and Man Shing Wong ${ }^{*}+{ }^{\dagger}$
}

\author{
${ }^{\dagger}$ Department of Chemistry, Hong Kong Baptist University, Kowloon Tong, Hong Kong SAR, China \\ ${ }^{\ddagger}$ Shenzhen Key Laboratory of Marine Biotechnology and Ecology, College of Life Sciences, Shenzhen University, Shenzhen 518060, \\ China \\ ${ }^{\S}$ Key Laboratory for Green Organic Synthesis and Application of Hunan Province, Key Laboratory of Environmentally Friendly \\ Chemistry and Application of Ministry of Education, College of Chemistry, Xiangtan University, Xiangtan 411105, China
}

Supporting Information

ABSTRACT: We report herein an investigation of carbazolebased cyanine, (E)-4-(2-(9-(2-(2-methoxyethoxy)ethyl)-9Hcarbazol-3-yl)-vinyl)-1-methyl-quinolin-1-iumiodide (SLM), as an effective theranostic agent for Alzheimer's disease $(\mathrm{AD})$. This cyanine exhibited desirable multifunctional and biological properties, including amyloid- $\beta(\mathrm{A} \beta)$-oligomerization inhibition, blood-brain barrier permeability, low neurotoxicity, neuroprotective effect against $\mathrm{A} \beta$-induced toxicities, high selectivity and strong binding interactions with $\mathrm{A} \beta$ peptide/species, good biostability, as well as strong fluorescence enhancement upon binding to $\mathrm{A} \beta$ species for diagnosis and therapy of $\mathrm{AD}$. This cyanine has been successfully applied to perform near-infrared in vivo imaging of $\mathrm{A} \beta$ species in transgenic $\mathrm{AD}$ mouse model. The triple transgenic $\mathrm{AD}$ mice intraperitoneally treated with SLM showed significant recovery of cognitive deficits. Furthermore, those SLM-treated mice exhibited a substantial decrease in both of oligomeric $\mathrm{A} \beta$ contents and tau proteins in their brain, which was attributed to the induction of autophagic flux. These findings demonstrated for the first time that SLM is an effective theranostic agent with in vivo efficacy for diagnosis and treatment of $\mathrm{AD}$ in mouse models.

\section{INTRODUCTION}

Alzheimer's disease $(\mathrm{AD})$ is the most prevalent neurodegenerative dementia, which leads to an impairment of various cognitive functions and memory loss, affecting 47 million people worldwide in 2015 . $^{1}$ Since $\mathrm{AD}$ is still incurable, it does place a huge burden to both the medical field and the society. Two of the pathological hallmarks of $\mathrm{AD}$ include the presence of extracellular amyloid- $\beta(\mathrm{A} \beta)$ plaques, primarily composed of misfolded $\mathrm{A} \beta_{(1-40)}$ and $\mathrm{A} \beta_{(1-42)}$ aggregates and intracellular tau neurofibrillary tangles, due to the accumulation of hyperphosphorylated tau proteins. ${ }^{2-4}$ Since $\mathrm{A} \beta$ peptides and tau proteins are widely believed to be involved in the pathogenesis of $\mathrm{AD}$, they represent the primary drug targets for the development of disease-modifying therapy in $\mathrm{AD} .^{5,6}$ Among various drug development strategies, targeting the overproduction and inefficient clearance of the $\mathrm{A} \beta$ peptides has constituted one of the primary focuses. ${ }^{7,8}$ Increasing evidence suggests that soluble $\mathrm{A} \beta$ oligomers are more neurotoxic than monomers and aggregates. ${ }^{9,10}$ Hence, the recent trials of the treatment approach for $\mathrm{AD}$ is to reduce the level and inhibit the formation of soluble toxic $\mathrm{A} \beta$ oligomers, which are believed to impair intracellular membranes leading to mitochondrial and lysosomal dysfunctions and further resulting in neuronal and synaptic damage, as implicated by the modified amyloid cascade hypothesis. The studies also showed that soluble $\mathrm{A} \beta$ oligomers would facilitate the tau pathology by influencing the signaling pathways that mediate the phosphorylation of the tau protein, thereby triggering $\mathrm{AD} .{ }^{11}$ Studies have indicated that the deposition of tau-associated neurofibrillary tangles correlates well with the disease progression of $\mathrm{AD}$ and thus it also becomes an important therapeutic target of $\mathrm{AD} .^{12,13}$

Meanwhile, $\mathrm{A} \beta$ oligomers can be used as predictive disease biomarkers for monitoring of progression and diagnosis of $\mathrm{AD}$. Among various detection techniques, noninvasive near-infrared (NIR) fluorescence imaging is the most intriguing, particularly for early diagnosis of $\mathrm{AD}$. A variety of fluorescence probes have been developed for detecting $\mathrm{A} \beta$ peptides; nonetheless, most of them are still not suitable for in vivo NIR imaging for their limited blood-brain barrier (BBB) permeability, intrinsic neurotoxicity, poor binding affinity toward $\mathrm{A} \beta$, and interference by autofluorescence.

Molecules that exhibit theranostic functions of $\mathrm{A} \beta$ oligomerization/aggregation inhibition and imaging capability of $\mathrm{A} \beta$ species have recently been reported; ${ }^{14-18}$ however, their

Received: March 14, 2018

Accepted: June 14, 2018

Published: June 25, 2018 
respective in vivo efficacy for cognitive improvement and simultaneously performing imaging of $\mathrm{A} \beta$ species in vivo in $\mathrm{AD}$ mouse model have not been explored and demonstrated. It is attributed to the diverse and strict criteria of an effective theranostic agent for therapy and diagnosis of $\mathrm{AD}$, which include good $\mathrm{BBB}$ permeability, low neurotoxicity, potent $\mathrm{A} \beta$ aggregation inhibition, neuroprotective effect against $\mathrm{A} \beta$ induced toxicity, high selectivity and targeting to $\mathrm{A} \beta$ peptide/ species, good biostability as well as strong fluorescence enhancement upon binding to $\mathrm{A} \beta$ peptide/species. ${ }^{19-21}$ Cyanine fluorophores are biocompatible and versatile as a fluorescence sensing probe for in vitro and in vivo bioimaging. $^{22-25}$ It was previously shown that carbazole-based quinolinium cyanines not only exhibited selective binding to $\mathrm{A} \beta$ peptides rendering the potential for direct imaging of $\mathrm{A} \beta$ species but also exerted strong inhibition on $\mathrm{A} \beta$ peptide aggregation, offering promise as a therapeutic agent for $\mathrm{AD} .^{24}$ We herein report that the carbazole-based cyanine, $(E)-4-(2-(9-$ (2-(2-methoxyethoxy) ethyl)-9H-carbazol-3-yl)-vinyl)-1-methyl-quinolin-1-iumiodide (SLM) (Figure 1) has been successfully

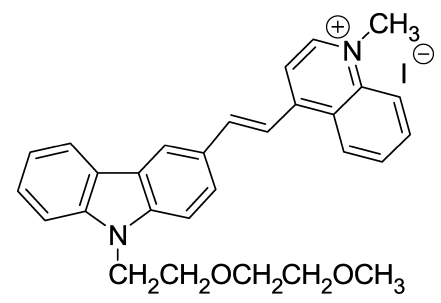

Figure 1. Molecular structure of carbazole-based cyanine, SLM.

used as an in vivo imaging agent for $\mathrm{A} \beta$ species in mouse model. In addition, administration of $\mathrm{A} \beta$-aggregation inhibition and neuroprotective SLM significantly protects triple transgenic (3 $\times$ Tg-AD) mice from cognitive decline, concomitant with a substantial decrease in contents of oligomeric $\mathrm{A} \beta$ and tau proteins in the cerebral hippocampal region. To the best of our knowledge, this is the first time that an effective theranostic agent shows integrated functions of (i) in vivo NIR imaging of $\mathrm{A} \beta$ species in $\mathrm{AD}$ mouse models as well as (ii) potent in vivo efficacy of improving cognitive deficit and reduction of $\mathrm{A} \beta$ plaques and tau content.

\section{RESULTS AND DISCUSSION}

NIR imaging can be a useful and promising tool for early $\mathrm{AD}$ diagnosis, as it can be applied to visualize and monitor the formation of $\mathrm{A} \beta$ aggregates and to evaluate the efficacy of the $\mathrm{AD}$ treatment in the animal model. Taking advantage of its strong binding to $\mathrm{A} \beta$ species $\left(K_{\mathrm{d}}\left(\mathrm{A} \beta_{1-40}\right)\right.$ of fibril $=13.1 \mu \mathrm{M}$, $K_{\mathrm{d}}\left(\mathrm{A} \beta_{1-40}\right)$ of monomer $=96.6 \mu \mathrm{M} ; K_{\mathrm{d}}\left(\mathrm{A} \beta_{1-42}\right)$ of fibril $=$ $11.4 \mu \mathrm{M}, K_{\mathrm{d}}\left(\mathrm{A} \beta_{1-42}\right)$ of monomer $\left.=40.2 \mu \mathrm{M}\right)$ that results in strong fluorescence enhancement (Table S1 and Figure S1), SLM shows great potential as in vivo $\mathrm{A} \beta$ NIR imaging agent. We demonstrated the application of SLM in detecting and imaging of $\mathrm{A} \beta$ species in a 9-month-old amyloid precursor proteins (APP)/PS1 transgenic ( $\mathrm{Tg}$ ) mouse in vivo. Figure 2a displays the fluorescence images of $\mathrm{Tg}$ and wild-type (WT) mice at different time points before and after intravenous injection of SLM at a dosage of $5 \mathrm{mg} / \mathrm{kg}$. As clearly seen, the fluorescence intensity from the brain of $\mathrm{Tg}$ mouse is significantly higher than that of WT at all time points recorded. The fluorescence signal also retained significantly longer in the $\mathrm{Tg}$ mouse when compared with that of the WT, which was attributed to the strong binding of SLM to the $\mathrm{A} \beta$ species in the brain of the $\mathrm{Tg}$ mouse. This is consistent with the results obtained from the semiquantitative kinetic clearance profile analysis of fluores-

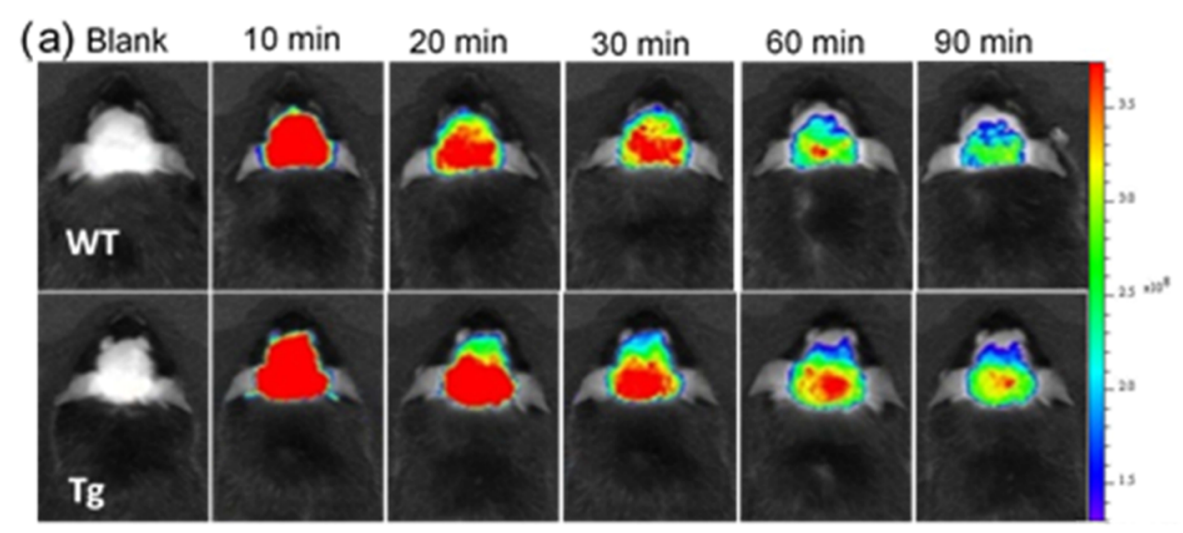

(b) Bright Field

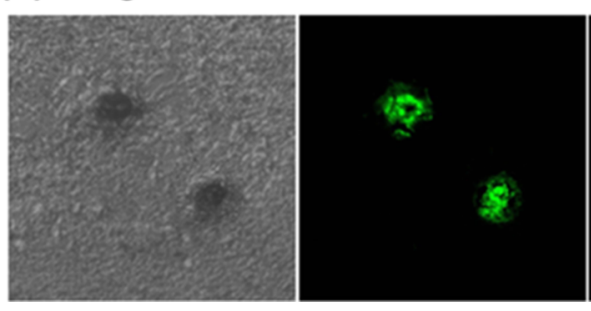

SLM

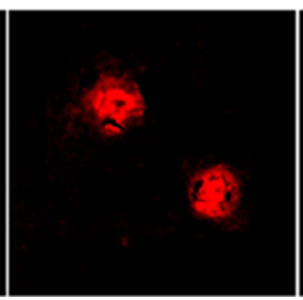

Merged

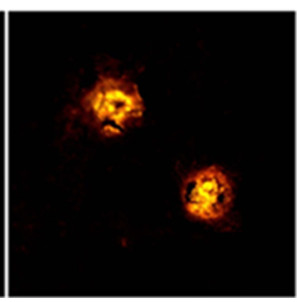

Figure 2. (a) Fluorescence images of $\mathrm{Tg}$ ( 9 months old) and wild-type mice at different time points before and after intravenous injection of SLM (5 $\mathrm{mg} / \mathrm{kg}$ ). $\lambda_{\mathrm{ex}}=535 \mathrm{~nm}, \lambda_{\mathrm{em}}=600-640 \mathrm{~nm}$. (b) Histological staining of the brain slices from 9-month transgenic mice stained with SLM via tail-vein injection $\left(\lambda_{\mathrm{ex}}=488 \mathrm{~nm}, \lambda_{\mathrm{em}}=640-680 \mathrm{~nm}\right)$ and co-stained with ThT $\left(\lambda_{\mathrm{ex}}=405 \mathrm{~nm}, \lambda_{\mathrm{em}}=460-490 \mathrm{~nm}\right)$. The images are $40 \times$ magnification of the selected regions. 
(a)

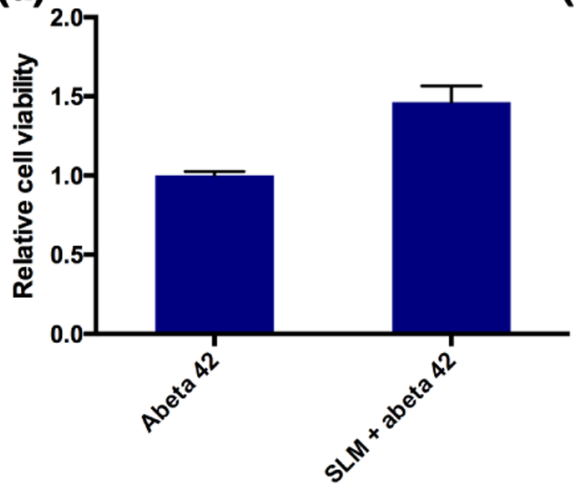

(b)

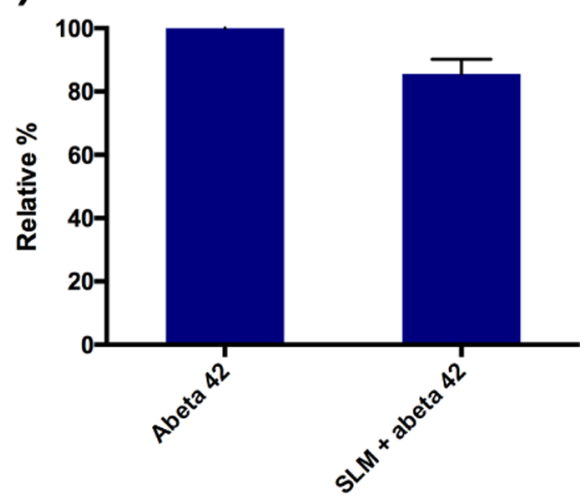

Figure 3. (a) Neuroprotective effect of the cyanine compounds against the toxicity induced by A $\beta_{(1-42)}$ on primary hippocampal cells. SLM was found to be neuroprotective, (b) the neuroprotective cyanine attenuated the $\mathrm{A} \beta_{(1-42)}$-induced reactive oxygen species (ROS) level on primary hippocampal cells. The relative percentage represented the cell death and ROS level of the A $\beta_{(1-42)}$-treated cells, respectively, in the presence and absence of SLM.

cence images of the brains of Tg and WT mice (Figure S4). The longer clearance time further confirmed the strong binding interactions of SLM with A $\beta$ species. Nonetheless, accurate quantification of SLM for its permeability and pharmacokinetics by liquid chromatography-mass spectrometry study would be definitely important for further clinical studies. To ascertain the targeting property of SLM toward A $\beta$ species, the brain slices of Tg mouse ( 9 months old) after tail-vein injection with SLM was ex vivo co-stained with $\mathrm{A} \beta$ plaque-specific thioflavin (ThT) dye. As shown in Figure $2 b$, the fluorescence of SLM overlapped well with that of ThT in the central core of the cluster plaques, indicating that SLM is highly specific to $\mathrm{A} \beta$ plaques. In addition to staining the $\mathrm{A} \beta$ plaques/fibrils, the weaker fluorescence of SLM was observed in the peripheral of the clusters, which could not be labeled by ThT. It is due to the fact that ThT only labels aggregated $\mathrm{A} \beta$ but SLM can also bind strongly with $\mathrm{A} \beta$ oligomers.

SLM also exhibits inhibition effect on the oligomerization of $\mathrm{A} \beta_{(1-42)}$, as evaluated by sodium dodecyl sulfate-polyacrylamide gel electrophoresis (SDS-PAGE) analysis (Figure S2), where it showed a smaller amount of dimeric $\mathrm{A} \beta_{(1-42)}$ formation in the presence of SLM. Besides, LC50 of SLM was determined to be $20 \mu \mathrm{M}$ using SH-SY5Y cells by MTT assay (Figure S3). Neuroprotective effect of inhibitor compounds is one of the important screening parameters for pharmaceutical potential in $\mathrm{AD}$ treatment. The neuroprotective effect of SLM against the more neurotoxic $\mathrm{A} \beta_{(1-42)}$ on primary hippocampal cells was then studied. The results, summarized in Figure 3, indicated that SLM showed significantly higher survival rate and, thus, beneficial to the neuronal cells that were incubated with $\mathrm{A} \beta_{(1-42)}$ over a period of $24 \mathrm{~h}$, highlighting tremendous promise of this cyanine for preventive and therapeutic treatment of $\mathrm{AD}$.

Given that elevation in oxidative stress constitutes parts of the causative factors for $\mathrm{A} \beta$-induced neurotoxicity, ${ }^{26,27}$ we investigated the neuroprotective effect of SLM against reactive oxygen species (ROS) in neuronal primary cells. A ROS fluorescent dye, carboxyl-2', $7^{\prime}$-dichlorofluorescein diacetate (carboxyl-DCFDA), was employed to monitor the ROS level in primary hippocampal cells that were exposed to $\mathrm{A} \beta_{(1-42)}$ in the presence and absence of the neuroprotective SLM. Indeed, a significant elevation of ROS level in the control cells was induced by the addition of $10 \mu \mathrm{M} \mathrm{A} \beta_{(1-42)}$ in $24 \mathrm{~h}$. The ROS level was decreased by about $20 \%$, as illustrated in Figure 3, when the neuronal cells were co-incubated with neuroprotective SLM.
These results unambiguously indicated that SLM could protect the health of the neuronal cells by attenuating the ROS level.

In view that SLM possessed all of the desired functional and biological properties for potential therapeutics for $\mathrm{AD}$, we then examined the in vivo efficacy of SLM against cognitive impairment using triple transgenic $\mathrm{AD}$ model mice $(3 \times \mathrm{Tg}$ $\mathrm{AD})$ expressing human gene mutants APPswe, PS1M146V, and tauP301L. These $3 \times \mathrm{Tg}-\mathrm{AD}$ mice showed intracellular $\mathrm{A} \beta$ at $3-$ 6 months of age and cognitive impairment at 6 months of age. The 8-month-old $3 \times \mathrm{Tg}$ - $\mathrm{AD}$ mice received the cyanine inhibitors, SLM, for 45 days $(2.25 \mathrm{mg} / \mathrm{kg} /$ day $)$ intraperitoneally. No obvious differences in body weight or changes in physical behavior (swimming speed) were observed among the groups during the 45 days administration (Figures S5 and S6). Morris water maze tests were performed after the 45 days SLM treatment. As shown in Figure 4a,b, the SLM-treated $3 \times \mathrm{Tg}-\mathrm{AD}$ mice exhibited a significantly shorter latency to escape onto the hidden platform, as compared to the control Tg mice on days 3, 4 , and $5(* P<0.05, n=19 ; * * P<0.001, n=19 ; * * * P<0.0001$,

(a)
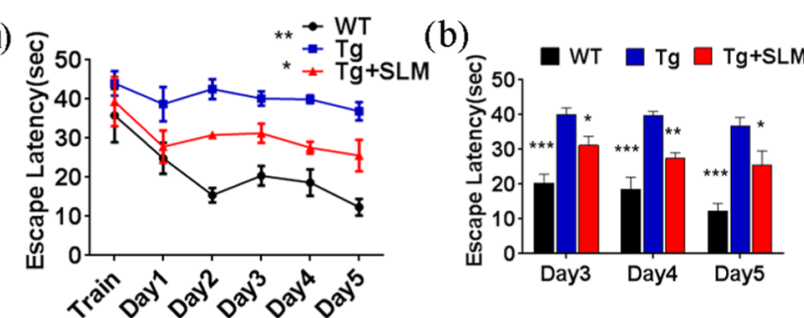

(c)
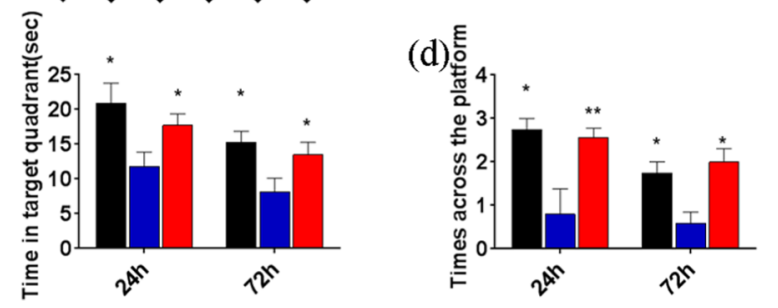

Figure 4. (a, b) Results of hidden platform tests in the Morris water maze experiment for the SLM-treated $3 \times \mathrm{Tg}-\mathrm{AD}$ mice, the control, and the WT, on training day and days $1-5(* P<0.05, n=19$; $* *<0.001, n$ $=19$; $* * * P<0.0001, n=19)$. (c, d) Results of the probe trial and the time spent in the previously learned platform quadrant for the WT, control, and the treated mice after 24 and $72 \mathrm{~h}$ of the hidden platform test. The data were analyzed by two-way analysis of variance (ANOVA). 

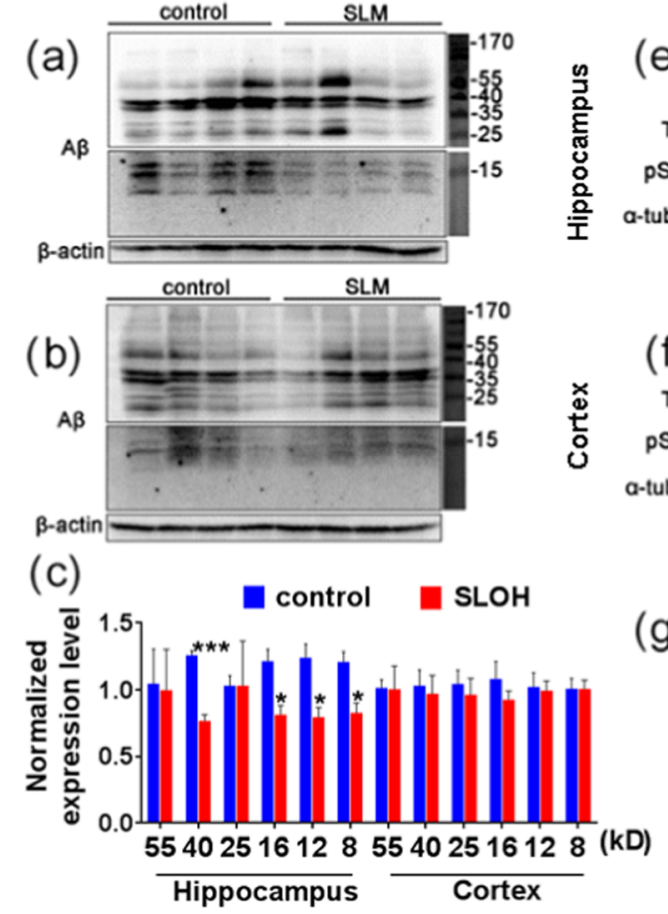

(d) $\mathrm{CA} 1$

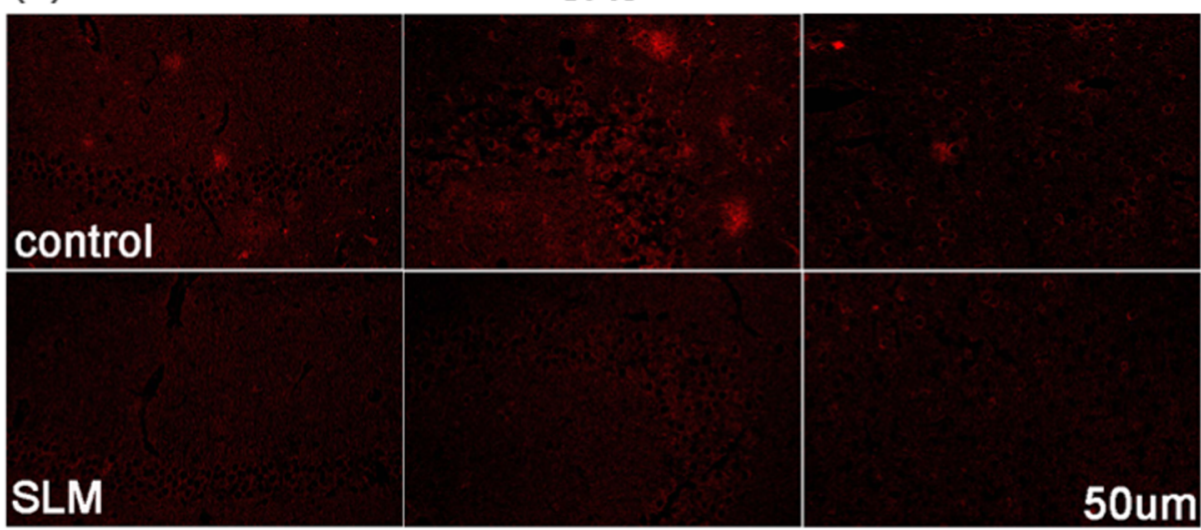

(h)

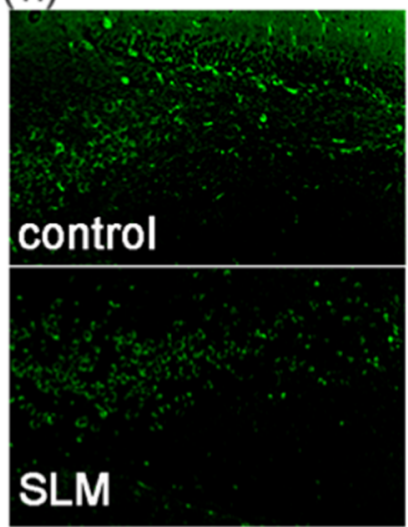

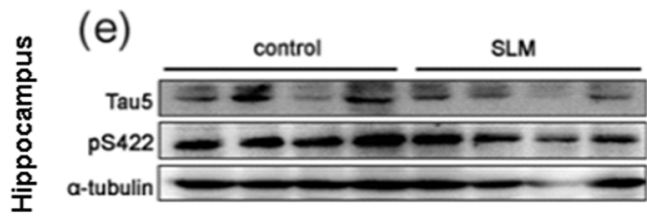

(f)

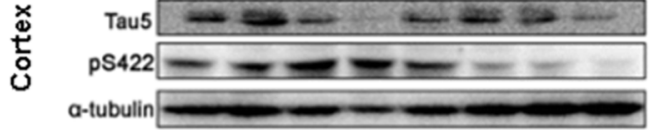

(g)

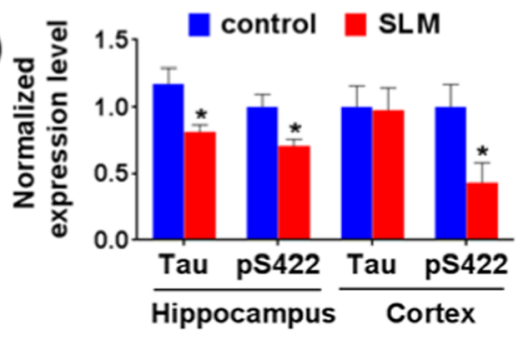

CA3

CA1

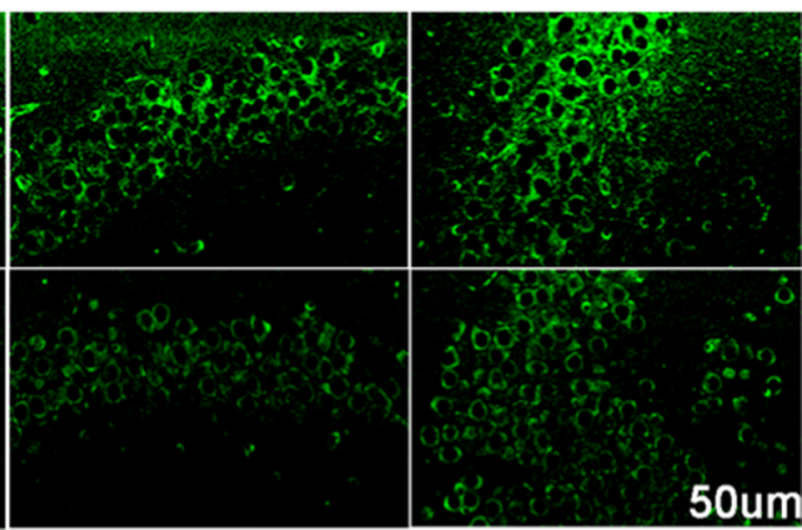

Figure 5. Levels of $\mathrm{A} \beta$ and tau in the hippocampal and cortical region of SLM-treated $3 \times \mathrm{Tg}-\mathrm{AD}$ mice were analyzed with the western blot and immunofluorescence. The protein contents of the brain lysates were analyzed with the western blot $((a-c)$ for oligomeric $A \beta$, (e-g) for tau, and pS422). Brain slices of the hippocampus and the cortex were immunostained for $A \beta(d)$ and tau (h).

$n=19)$. Moreover, the SLM-treated $3 \times \mathrm{Tg}-\mathrm{AD}$ mice traveled to the previously learned platform quadrant more frequently than the control ones, as assessed by the probe test (Figure 4c,d). The time spent in the previously learned platform quadrant was also longer for the treated $3 \times \mathrm{Tg}-\mathrm{AD}$ mice after 24 and $72 \mathrm{~h}$ of the hidden platform test. All these results consistently support that the SLM-treated $3 \times \mathrm{Tg}-\mathrm{AD}$ mice showed a significant cognitive improvement, not only enhancing learning skills in the hidden 
platform test but also improving the spatial memory in the probe trial.

We also examined the $\mathrm{A} \beta$ and tau contents in the brain of the SLM-treated $\mathrm{Tg}$ mice via the western blot analysis and immunofluorescence after the cognitive test. Remarkably, the A $\beta$ content substantially decreased, particularly those of the toxic $\mathrm{A} \beta$ oligomers with $8,12,16,25,40$, and $55 \mathrm{kDa}$ as the total tau (tau-5) and phosphorylated tau (ps422) proteins in hippocampal regions, as compared with those of the control (see Figure $5 \mathrm{a}-\mathrm{c}, \mathrm{e}-\mathrm{g}$ ), suggesting that the cyanine inhibitor can ameliorate both $\mathrm{A} \beta$ and tau pathologies in the $3 \times \mathrm{Tg}-\mathrm{AD}$ mouse model. The presence of $\mathrm{A} \beta$ and tau, which was visualized by immunostaining in the brain slices of the treated $3 \times \mathrm{Tg}$ - $\mathrm{AD}$ mice, was obviously reduced compared to those of the untreated $3 \times \mathrm{Tg}-\mathrm{AD}$ mice (Figure $5 \mathrm{~d}, \mathrm{~h}$ ). The activity of glycogen synthase kinase-3 (GSK3) can be inhibited by Akt-mediated phosphorylation at Ser9 of GSK3 $\beta$. The level of inactive phosphorylated glycogen synthase kinase- $3 \beta$ (p-GSK3 $\beta$ ) was significantly higher in the SLM-treated Tg mice, as well as the increase in the ratio of $\mathrm{p}-\mathrm{GSK} 3 \beta / \mathrm{GSK} 3 \beta$, indicating the reduction of GSK $3 \beta$ activity, which provides a direct insight into the decrease of the phosphorylated tau content (Figure $\mathrm{S} 7 \mathrm{c}, \mathrm{d})$. These results also indicate that the reduction of the toxic $\mathrm{A} \beta$ oligomers level alleviates the tau dysfunction in the SLMtreated Tg mice.

Increasing evidence implies that dysfunctional autophagy plays a crucial role in the $\mathrm{AD}$ pathogenesis, such as the failure of A $\beta$ clearance. $^{28,29}$ Thus, we have investigated whether SLM would modulate autophagic dysfunction. It was found that the levels of amyloid precursor proteins (APPs) and the $\beta$-site APPcleaving enzyme 1 (Bace 1 ) in the SLM-treated Tg mice were similar to those of the control, suggesting that the $\mathrm{A} \beta$ production was not disrupted or suppressed (Figure S7a,b). On the other hand, SLM treatment yielded a significantly reduced level of a key autophagy gatekeeper, phosphorylated form of mammalian target of rapamycin (mTOR), which was concomitant with substantially attenuated phosphorylation of Akt, an upstream effector of mTOR, that modulates its activation as well as a significant increase in a proautophagic protein, the mammalian orthologue of yeast Atg6 (Beclin 1) level, as compared with that of the control (see Figure S8), strongly suggesting autophagic induction. ${ }^{30-32}$ Furthermore, both the levels of microtubuleassociated protein light chain 3-II (LC3-II), which was degraded by lysosomal hydrolases in autophagolysosomes and the LC3associated p62 protein (sequestosome 1), a marker of autophagic flux, were found to be markedly decreased. The level of the lysosomal protease, cathepsin D (CatD), that mediates the degradation in autophagolysosomes was found to be significantly increased. All these results unanimously support the fact that autophagic pathways were significantly modulated in the SLM-treated $3 \times \mathrm{Tg}-\mathrm{AD}$ mice relative to the untreated counterparts, resulting in the reduction of $\mathrm{A} \beta$ deposits and tau contents as well as recovery of cognitive deficits in the $\mathrm{AD}$ mouse model.

\section{CONCLUSIONS}

A systematic evaluation of carbazole-based cyanine, SLM, including $\mathrm{A} \beta$ binding behavior, $\mathrm{A} \beta_{1-42}$ oligomerization inhibition, cytotoxicity, neuroprotective effect, BBB permeability as well as in vivo imaging and efficacy as a novel and effective theranostic agent for diagnosis and treatment of $\mathrm{AD}$ was investigated. Remarkably, SLM possessing all of the desirable properties as an in vivo imaging agent can perform NIR imaging of $\mathrm{A} \beta$ species in vivo. Furthermore, the SLM-treated $3 \times \mathrm{Tg}-\mathrm{AD}$ mice showed substantial improvement in cognitive functions, including spatial learning and memory. SLM also exhibited the capability to significantly decrease the oligomeric $\mathrm{A} \beta$ contents, as well as reduce t-tau (tau-5) and p-tau protein (ps422) levels in the brain of the $3 \times \mathrm{Tg}-\mathrm{AD}$ mice, which was attributed to the modulation of autophagic flux. The present study represents the first in vivo evidence that SLM can not only conduct the imaging of $\mathrm{A} \beta$ species in vivo but also ameliorate both $\mathrm{A} \beta$ and tau pathologies concomitant with a reduction in the levels of toxic $\mathrm{A} \beta$ oligomers and $\mathrm{p}$-tau protein. SLM also represents the first effective theranostic agent for the therapy and diagnosis of $\mathrm{AD}$. Our findings open up a new vista to develop more potent theranostic agents for clinical applications in $\mathrm{AD}$.

\section{MATERIALS AND METHODS}

Sample Preparation of $\mathbf{A} \boldsymbol{\beta}_{(1-40)}$ Fibril. Stock monomeric $\mathrm{A} \beta_{(1-40)}$ (Invitrogen) solution was prepared by dissolving $1 \mathrm{mg}$ of $\mathrm{A} \beta_{(1-40)}$ powder in $400 \mu \mathrm{L}$ of $0.02 \%$ ammonia solution without any purification and stored at $-20{ }^{\circ} \mathrm{C}$ until use. $\mathrm{A} \beta_{(1-40)}$ fibril was prepared by diluting the stock monomeric $\mathrm{A} \beta_{(1-40)}$ to $50 \mathrm{mM}$ with filtered phosphate buffer solution and incubated at $37{ }^{\circ} \mathrm{C}$ for $24 \mathrm{~h}$.

Sample Preparation of $\mathbf{A} \boldsymbol{\beta}_{(1-42)}$ Aggregates. Stock monomeric $\mathrm{A} \beta_{(1-42)}$ (rPeptide) solution was prepared by dissolving $1 \mathrm{mg}$ of $\mathrm{A} \beta_{(1-42)}$ powder in $400 \mu \mathrm{L}$ of $1 \%$ ammonium solution without any purification and stored at $-20{ }^{\circ} \mathrm{C}$ until use. The aggregate was prepared by diluting the stock monomeric solution to $200 \mu \mathrm{M}$ with $10 \mathrm{mM}$ filtered $\mathrm{HCl}$ and incubated at $37{ }^{\circ} \mathrm{C}$ for 6 days.

Fluorescence Titration. SLM solution of 400 and $50 \mu \mathrm{M}$ $\mathrm{A} \beta_{(1-40)}$ monomer/fibril and $\mathrm{A} \beta_{(1-42)}$ monomer/aggregate solution were prepared in phosphate buffer. By mixing a corresponding amount of cyanine solution, buffer, and a constant amount of $\mathrm{A} \beta$ solution, $20 \mu \mathrm{L}$ of mixture solution with different SLM-to-A $\beta$ ratios were prepared. Emission measurement was obtained on PTI Time Master C-720.

SDS-PAGE. Monomeric A $\beta_{(1-42)}$ was first treated with $100 \%$ hexafluoroisopropanol (HFIP). The residual HFIP was removed under vacuum, and the resulting peptide was stored at $-20^{\circ} \mathrm{C}$. The oligomeric $\mathrm{A} \beta_{(1-42)}$ was prepared by resuspending the treated monomeric $\mathrm{A} \beta_{(1-42)}$ in anhydrous dimethyl sulfoxide (DMSO) with a final concentration of $5 \mathrm{mM}$. The peptide solution was diluted to a final concentration of $100 \mu \mathrm{M}$ with $\mathrm{F}$ 12 (without phenol red) culture medium and co-incubated with an appropriate amount of SLM solution at $4{ }^{\circ} \mathrm{C}$ for $24 \mathrm{~h}$. All samples were then treated with PICUP and followed by SDSPAGE and Coomassie Blue staining.

Cell Assay Procedures. Cell Culture and Medium. All cell culture reagents were purchased from Gibco. Human neuroblastoma SH-SY5Y cell lines were cultured in Dulbecco's modified Eagle's medium (DMEM)/Ham's F-12 medium, supplemented with $10 \%$ fetal bovine serum. Cells were grown in a humidified cell incubator at $37{ }^{\circ} \mathrm{C}$ under a $5 \% \mathrm{CO}_{2}$ atmosphere.

Primary Cell Isolation. All animal experiments were performed under the guidelines of Animals (Control of Experiments) Ordinance, approved by the Committee on the Use of Human and Animal Subjects in Teaching and Research of the Hong Kong Baptist University and conformed to The Principles of Laboratory Animal Care (NIH publication no. 8623 , revised 1985). Sprague-Dawley rats were obtained from the Chinese University of Hong Kong. Hippocampus neuronal cells 
were isolated from 1-day-old Sprague-Dawley rats. Briefly, the brains were placed in cold Hank's balanced salt solution (HBSS; Gibco), and the hippocampus cells were extracted. The cells were resuspended in DMEM/F-12 medium (Gibco) with $10 \%$ fetal bovine serum (Gibco) and papain solution (SigmaAldrich) in $2 \mu \mathrm{g} / \mathrm{mL}$ was added into the system. The mixture was incubated at $37^{\circ} \mathrm{C}$ for $20 \mathrm{~min}$ under gentle shaking. The solution was purified by a $0.4 \mu \mathrm{m}$ nylon filter (BD falcon), and the filtrate was further centrifuged at $1000 \mathrm{rpm}$ for $5 \mathrm{~min}$. The pellet containing the dissociated neurons was resuspended in neurobasal medium (Gibco) with supplements 2\% B-27 (B-27 Supplement 50; Gibco), 0.2\% penicillin (PSN; Gibco), and $0.25 \%$ glutamax (GlutaMAX-I 100X; Gibco). The centrifugation steps were repeated twice. The cells were plated into a polyD-lysine (Sigma-Aldrich)-coated plate and incubated in a humidified incubator at $37{ }^{\circ} \mathrm{C}$ with $5 \% \mathrm{CO}_{2}$ for 7 days before treatment.

Cell Viability Assay. Exponentially growing SH-SY5Y cells were plated onto 96-well plates in cell culture medium at a density of $5 \times 10^{5}$ cells $/ \mathrm{mL} /$ well. The day after plating, the culture medium was replaced with $0.2 \%$ serum containing $24 \mu \mathrm{L}$ of SLM at a final concentration ranging from $700 \mathrm{nM}$ to $800 \mu \mathrm{M}$ for determining LC50. After $24 \mathrm{~h}$ incubation at $37{ }^{\circ} \mathrm{C}$, the culture medium of each well was replaced with $100 \mu \mathrm{L}$ of 3-(4,5dimethylthiazol-2-yl)-2,5-diphenyltetrazolium bromide (MTT) solution $(0.25 \mathrm{mg} / \mathrm{mL}$; Sigma-Aldrich $)$ and further incubated at $37{ }^{\circ} \mathrm{C}$ for $3 \mathrm{~h}$. The MTT solution was then aspirated off, followed by the addition of $100 \mu \mathrm{L}$ of DMSO (Sigma-Aldrich) to dissolve the formazan crystals. The plates were agitated on a plate shaker for $15 \mathrm{~min}$, and the absorbance at $540 \mathrm{~nm}$ with a reference absorbance set to $690 \mathrm{~nm}$ was recorded by the microplate reader (BioTek). Wells without cells were referred to as blanks and were subtracted as background from each sample. For the neuroprotective studies on the primary hippocampal cells, SLM at a final concentration of $10 \mu \mathrm{M}$ was applied together with monomeric $\mathrm{A} \beta_{(1-42)}$ at a concentration of $10 \mu \mathrm{M}$. Results were expressed as the relative percentage of control. The relative percentage of cytotoxicity was calculated as ((MTTcontrol MTTbg) - (MTT SLM - MTTbg))/(MTTcontrol MTTbg) $\times 100 \%$. Three independent trials were analyzed, and the results were expressed as the mean \pm standard error of mean (SEM).

ROS Measurement. Primary hippocampal cells were plated onto a 96 black plate at a density of $5 \times 10^{5}$ cells $/ \mathrm{mL}$ in cell culture medium per well. The day after plating, the culture medium was replaced with $0.2 \%$ serum, containing $100 \mu \mathrm{M} 5$ (and-6)-carboxy- $2^{\prime}, 7^{\prime}$-dichlorofluorescein diacetate (carboxyDCFDA) purchased from Invitrogen (Camarillo, CA). The medium was then incubated in dark in a humidified cell incubator at $37^{\circ} \mathrm{C}$ under a $5 \% \mathrm{CO}_{2}$ atmosphere for $30 \mathrm{~min}$. The medium was removed, and the wells were washed twice with phosphate-buffered saline (PBS). The cells were then resuspended in fresh culture medium and incubated for 30 min. Afterward, the medium was replaced by SLM together with monomeric $\mathrm{A} \beta_{(1-42)}$ in 1:1 ratio in HBSS and incubated in dark at $37{ }^{\circ} \mathrm{C}$ for $24 \mathrm{~h}$. The fluorescence intensity of cells was measured by a microplate reader (Tecan Schweiz AG, Switzerland) with excitation/emission at 485/530 $\mathrm{nm}$. The values were expressed as fluorescence intensity ratio relative to control (treated with monomeric $\mathrm{A} \beta_{(1-42)}$ only).

In Vivo and ex Vivo Study on Blood-Brain Barrier Permeability. First, 9-month-old APP/PS1 Tg mice with agematching wild-type mice as control were anesthetized under isoflurane gas $(2.0 \mathrm{~mL} / \mathrm{min})$, supplemented with oxygen $(1.0$ $\mathrm{mL} / \mathrm{min}$ ) until motionless, then followed by the injection of 100 $\mu \mathrm{L}$ of SLM $(5 \mathrm{mg} / \mathrm{kg})$ via the tail vein. Fluorescence imaging of the brain section was captured by an IVIS imaging system at different postinjection time points. All of the images were acquired using an excitation filter at $\sim 535 \mathrm{~nm}$ and an emission filter at $\sim 600-640 \mathrm{~nm}$, with an exposure time set at $1 \mathrm{~s}$. The resultant images were further analyzed using Living Image software. The normalized fluorescence intensity of brain sections was obtained by dividing the radiant efficiency by the background fluorescence of each mouse [i.e., $F(t) / F($ pre $)]$ at the selected region of interest. $F(t)$ and $F($ pre $)$ referred to the fluorescence intensity of the time point of interest and the background fluorescence signal, respectively. For the ThT costaining assay, $\mathrm{Tg}$ mice were sacrificed and the brain tissues of Tg mice were collected after $1 \mathrm{~h}$ postinjection of SLM. The brain was then embedded in optimum cutting temperature compound and sliced into $20 \mu \mathrm{m}$ in thickness for micrography. The brain slices were immersed in a solution cocktail, containing $1.0 \mu \mathrm{M}$ ThT solution and $10 \%$ DMSO for $5 \mathrm{~min}$, then washed with $40 \%$ ethanol for $2 \mathrm{~min}$, and rinsed with water for $30 \mathrm{~s}$. Finally, the fluorescence images of the brain slices were recorded by laser scanning confocal microscope, $40 \times$ oil-immersion type objective.

Animals and Experimental Procedure. The protocol that we adopted was approved by the Animal Ethical and Welfare Committee of Shenzhen University (Permit Number: AEWC20140615-002) of China. All operations were performed under ether anhydrous inhalation of anesthesia to minimize suffering.

Animal Model. $3 \times \mathrm{Tg}-\mathrm{AD}$ mice, expressing human gene mutants APPswe, PS1M146V, and tauP301L and wild-type (WT) mice of same genetic background, were purchased from the Jackson laboratory (BarHarbor, ME) for breeding. Male and female mice were kept in a separated cage with ad libitum food and water supply with $12 \mathrm{~h}$ light/dark cycle prior to treatment.

Drug Administration. For the drug treatment, the mice were divided into two groups and each group contained ten 8-monthold male mice and nine 8-month- old female mice. Group 1 was the control $3 \times \mathrm{Tg}$ mice; they received daily intraperitoneal injection of $100 \mu \mathrm{L} \mathrm{PB}$, whereas group $2(3 \times \mathrm{Tg}$ mice $)$ received daily intraperitoneal injection of $100 \mu \mathrm{L} \mathrm{SLM}$ at $2.25 \mathrm{mg} / \mathrm{kg}$ for 45 days. All procedures followed institutional guidelines and were approved by the local state authorities for animal welfare.

Morris Water Maze Test. After treatment, the spatial reference memory of the mice was examined by Morris water maze. The test generally consisted of three parts: (i) 1 day training, where the mice were placed in a $26-29{ }^{\circ} \mathrm{C}$ circular aluminum tank ( $1.5 \mathrm{~m}$ in diameter). The tank was virtually divided into four quadrants (north, east, south, and west) and a visible platform (10 cm in diameter), which is $1 \mathrm{~cm}$ higher than the water surface. The mice were placed in one of the quadrants. During the training, the mice could find and escape onto the platform. If the mouse failed to find the platform within $60 \mathrm{~s}$, it was manually guided to the platform and allowed to stay on the platform for $10 \mathrm{~s}$. (ii) After the training, the mice were then placed in the same circular platform to perform a 5-day hidden platform test. (iii) Probe trials were performed on day 7 (24 h) and day $9(72 \mathrm{~h})$. The platform was removed, and the mice were placed in the quadrant of the pool, which was located opposite to the previous platform quadrant. All of the behavior of the mice, including the distance traveled to the target quadrant and the number of times they passed the platform, was recorded by 
automated video tracking system, and the data were analyzed by two-way ANOVA.

Protein Extraction from the Brain. After the behavioral study, the mice were killed under anesthesia. Half of the brains were immediately removed, and hippocampus was separated from cortex carefully and the tissues were frozen on ice, stored at $-80{ }^{\circ} \mathrm{C}$ prior to western blot analysis. To analyze the protein content in the cortex and hippocampus region, the brain sections were first lysed by ultrasonic fragmentation for $1 \mathrm{~min}$ in buffer solution (cell lysis buffer for western blot and IP; Beyotime; Shanghai, China) with protease (1:200, PMSF; Beyotime, Shanghai, China) and phosphatase (1:100, PhosSTOP; Roche, Basel, Switzerland) inhibitors. Tissue extracts were centrifuged at $12000 \mathrm{rpm}$ for $30 \mathrm{~min}$, and the supernatants were collected for further analysis.

Western Blot. The protein content in the brain lysates were determined by the BCA protein assay kit (Beyotime, China), and $30 \mu \mathrm{g}$ of proteins were resolved in a $12 \%$ SDS-PAGE gel, then transferred to a nitrocellulose membrane in the range of 45-90 min, according to molecular weight of the protein. For antibody staining, the membrane was first blocked with 5\% skim milk to reduce nonspecific binding, followed by the overnight incubation with the corresponding diluted primary antibodies (see Table S1) at $4{ }^{\circ} \mathrm{C}$. Afterward, the membrane was washed thrice and further incubated with corresponding secondary 1:5000 diluted antibodies, horseradish peroxidase (HRP)conjugated immunoglobulin (IgG) antimouse (1:5000; Neobioscience, China), and antirabbit (1:5000; Neobioscience, China). The supersignal chemiluminescent substrate (Thermo) was added to visualize HRP activity on Fuji films (GE Healthcare, U.K.). The protein concentrations in the immunoblots were determined by software Quantity One. The statistical significance of the test was performed by using $t$-test analysis function in GraphPad Prism 5.0. Data were presented as the mean + standard error of mean (SEM) with $95 \%$ confidence interval (Table 1).

Immunohistochemistry and Immunofluorescence. The brains obtained in the previous section (Materials and Methods section) were bisected in the mid-sagittal plane. The left hemisphere was fixed in $4 \%$ formaldehyde for $24-36 \mathrm{~h}$ and soaked in different concentrations of ethanol $(30,50,75,85,95$,

\section{Table 1. Information of Purchased Antibodies}

\begin{tabular}{lll}
\multicolumn{1}{c}{ antibody } & \multicolumn{1}{c}{ catalog \# } & \multicolumn{1}{c}{ source } \\
full-length APP & ab2072 & Abcam \\
Bace 1 & 5606 & CST $^{a}$ \\
A $\beta$ & 9888 & CST \\
tau-5 & MN1000 & Life Technologies \\
ps422 & $2612-1$ & Epitomics \\
GSK3 $\beta$ & 9832 & CST \\
p-GSK3 $\beta$ & 5558 & CST \\
PP2A & 2259 & CST \\
mTOR & 2983 & CST \\
p-mTOR & 2971 & CST \\
p70S6k & 2708 & CST \\
p-p70S6k & 9205 & CST \\
Beclin 1 & 3495 & CST \\
LC3 & GTX116080 & GeneTex \\
P62 & GTX1006856 & GeneTex \\
cathepsin D & GTX62063 & GeneTex
\end{tabular}

${ }^{a} \mathrm{CST}=$ Cell Signaling Technology. and $100 \%)$. Tissues were moved to xylene and were then paraffin-embedded. Immunohistochemistry was performed on 5 $\mu \mathrm{m}$ sagittal paraffin sections. The sections were then treated with $0.3 \% \mathrm{H}_{2} \mathrm{O}_{2}$ in $0.01 \mathrm{M}$ PBS to block endogenous peroxidases and incubated with $70 \%$ formic acid for $3 \mathrm{~min}$. The sections were then treated with fetal calf serum for $15 \mathrm{~min}$ at room temperature to block any nonspecific binding, followed by the immunostaining of mouse polyclonal antibodies against $\mathrm{A} \beta_{(1-42)}$ (1:300; Cell Signaling Technology) overnight at $4{ }^{\circ} \mathrm{C}$. After incubation, the slices were rinsed thrice with PBS. Subsequently, tissues were incubated with Alexa Fluor 488-conjugated Fab fragments of goat antimouse immunoglobulin ( IgG) (H_L) for $2 \mathrm{~h}$ (1:500; Invitrogen). After several washes, tissues were mounted using an antifading mounting medium and air-dried away from light for confocal imaging. For immune-fluorescent staining, slices were incubated with tau- 5 specific primary antibody (1:300, Abcam) overnight at $4{ }^{\circ} \mathrm{C}$, followed by hightemperature heating to repair antigen. After incubation, the slices were rinsed thrice with PBS. Tissues were then incubated with Alexa Fluor 488-conjugated Fab fragments of goat antimouse immunoglobulin (IgG) (H_L) for $2 \mathrm{~h}$ (1:500; Invitrogen). After several washes, tissues were mounted using an antifading mounting medium and air-dried for confocal imaging.

\section{ASSOCIATED CONTENT}

\section{Supporting Information}

The Supporting Information is available free of charge on the ACS Publications website at DOI: 10.1021/acsomega.8b00475.

Synthesis of SLM; physical properties of SLM; fluorescence titration; oligomerization inhibition; MTT assay of SLM; retention of SLM in brain; body weights of mice after treatment; swimming speed of mice; expression level of $\mathrm{p}-\mathrm{GSK} 3 \beta$, GSK $3 \beta$, APP, and Bace 1 ; expression of autophagy-related proteins; NMR spectra of SLM (PDF)

\section{AUTHOR INFORMATION}

\section{Corresponding Authors}

*E-mail: lilys@szu.edu.cn (G.S.).

*E-mail: hwli@hkbu.edu.hk (H.W.L.).

*E-mail: mswong@hkbu.edu.hk (M.S.W.).

ORCID -

Hung-Wing Li: 0000-0003-4840-1965

Man Shing Wong: 0000-0001-8141-9791

\section{Author Contributions}

"Y.L., C.C., and D.X. contributed equally to this work.

Notes

The authors declare no competing financial interest.

\section{ACKNOWLEDGMENTS}

This work was supported by the Health and Medical Research Fund (HMRF 01122066) from the Hong Kong Government, and Collaborative Research Fund of Hong Kong Research Grant Council (C2012-15G). We are also thankful for the support of the National Natural Sciences Foundation of China (nos 81400847 and 21675135).

\section{REFERENCES}

(1) Qian, X.; Hamad, B.; Dias-Lalcaca, G. The Alzheimer disease market. Nat. Rev. Drug Discovery 2015, 14, 675-676. 
(2) Wood, H. Alzheimer disease: Evidence for trans-synaptic and exosynaptic tau propagation in Alzheimer disease. Nat. Rev. Neurol. 2015, 665.

(3) Serrano-Pozo, A.; Hyman, B. T. Alzheimer Disease: Alzheimer dementia with sparse amyloid[mdash] AD mimic or variant? Nat. Rev. Neurol. 2015, 674.

(4) Ittner, L. M.; Götz, J. Amyloid- $\beta$ and tau - a toxic pas de deux in Alzheimer's disease. Nat. Rev. Neurosci. 2011, 12, 67-72.

(5) Hampel, H.; Mitchell, A.; Blennow, K.; Frank, R. A.; Brettschneider, S.; Weller, L.; Moller, H. J. Core biological marker candidates of Alzheimer's disease - perspectives for diagnosis, prediction of outcome and reflection of biological activity. J. Neural Transm. 2004, 111, 247-272.

(6) Panza, F.; Frisardi, V.; Solfrizzi, V.; Imbimbo, B. P.; Logroscino, G.; Santamato, A.; Greco, A.; Seripa, D.; Pilotto, A. Immunotherapy for Alzheimer's disease: from anti-beta-amyloid to tau-based immunization strategies. Immunotherapy 2012, 4, 213-238.

(7) Bates, K. A.; Verdile, G.; Li, Q. X.; Ames, D.; Hudson, P.; Masters, C. L.; Martins, R. N. Clearance mechanisms of Alzheimer's amyloid[beta] peptide: implications for therapeutic design and diagnostic tests. Mol. Psychiatry 2009, 14, 469-486.

(8) Mandavilli, A. The amyloid code. Nat. Med. 2006, 12, 747-751. (9) Ladiwala, A. R. A.; Litt, J.; Kane, R. S.; Aucoin, D. S.; Smith, S. O.; Ranjan, S.; Davis, J.; Van Nostrand, W. E.; Tessier, P. M. Conformational Differences between Two Amyloid beta Oligomers of Similar Size and Dissimilar Toxicity. J. Biol. Chem. 2012, 287, 24765-24773.

(10) Stefani, M. Structural features and cytotoxicity of amyloid oligomers: Implications in Alzheimer's disease and other diseases with amyloid deposits. Prog. Neurobiol. 2012, 99, 226-245.

(11) Musiek, E. S.; Holtzman, D. M. Three dimensions of the amyloid hypothesis: time, space and 'wingmen'. Nat. Neurosci. 2015, 800-806.

(12) Miller, E. C.; Teravskis, P. J.; Dummer, B. W.; Zhao, X. H.; Huganir, R. L.; Liao, D. Z. Tau phosphorylation and tau mislocalization mediate soluble A beta oligomer-induced AMPA glutamate receptor signaling deficits. Eur. J. Neurosci. 2014, 39, 1214-1224.

(13) Giacobini, E.; Gold, G. Alzheimer disease therapy[mdash]moving from amyloid-[beta] to tau. Nat. Rev. Neurol. 2013, 9, 677-686.

(14) Rajasekhar, K.; Narayanaswamy, N.; Murugan, N. A.; Kuang, G. L.; Agren, H.; Govindaraju, T. A High Affinity Red Fluorescence and Colorimetric Probe for Amyloid beta Aggregates. Sci. Rep. 2016, 6, No. 23668.

(15) Rajasekhar, K.; Narayanaswamy, N.; Murugan, N. A.; Viccaro, K.; Lee, H. G.; Shah, K.; Govindaraju, T. A beta plaque-selective NIR fluorescence probe to differentiate Alzheimer's disease from tauopathies. Biosens. Bioelectron 2017, 98, 54-61.

(16) Rajasekhar, K.; Suresh, S. N.; Manjithaya, R.; Govindaraju, T. Rationally Designed Peptidomimetic Modulators of A beta Toxicity in Alzheimer's Disease. Sci. Rep. 2015, 5, No. 8139.

(17) Rajasekhar, K.; Narayanaswamy, N.; Mishra, P.; Suresh, S. N.; Manjithaya, R.; Govindaraju, T. Synthesis of Hybrid Cyclic Peptoids and Identification of Autophagy Enhancer. ChemPlusChem 2014, 79, $25-30$.

(18) Rajasekhar, K.; Chakrabarti, M.; Govindaraju, T. Function and toxicity of amyloid beta and recent therapeutic interventions targeting amyloid beta in Alzheimer's disease. Chem. Commun. 2015, 51, 1343413450.

(19) Citron, M. Strategies for disease modification in Alzheimer's disease. Nat. Rev. Neurosci. 2004, 5, 677-685.

(20) Sheridan, C. J\&J's billion dollar punt on anti-amyloid antibody. Nat. Biotechnol. 2009, 27, 679-681.

(21) Wang, Q. M.; Yu, X.; Li, L. Y.; Zheng, J. Inhibition of Amyloidbeta Aggregation in Alzheimer's Disease. Curr. Pharm. Des. 2014, 20, $1223-1243$.

(22) Yang, W.; Wong, Y.; Ng, O. T. W.; Bai, L.-P.; Kwong, D. W. J.; Ke, Y.; Jiang, Z.-H.; Li, H.-W.; Yung, K. K. L.; Wong, M. S. Inhibition of Beta-Amyloid Peptide Aggregation by Multifunctional CarbazoleBased Fluorophores. Angew. Chem., Int. Ed. 2012, 51, 1804-1810.
(23) Guo, L.; Chan, M. S.; Xu, D.; Tam, D. Y.; Bolze, F.; Lo, P. K.; Wong, M. S. Indole-based Cyanine as a Nuclear RNA-Selective TwoPhoton Fluorescent Probe for Live Cell Imaging. ACS Chem. Biol. 2015, $10,1171-1175$.

(24) Yang, W.; Chan, P. S.; Chan, M. S.; Li, K. F.; Lo, P. K.; Mak, N. K.; Cheah, K. W.; Wong, M. S. Two-photon fluorescence probes for imaging of mitochondria and lysosomes. Chem. Commun. 2013, 49, $3428-3430$

(25) Li, Y.; Xu, D.; Ho, S.-L.; Li, H.-W.; Yang, R.; Wong, M. S. A theranostic agent for in vivo near-infrared imaging of $\beta$-amyloid species and inhibition of $\beta$-amyloid aggregation. Biomaterials 2016, 94, 84-92.

(26) Barnham, K. J.; Masters, C. L.; Bush, A. I. Neurodegenerative diseases and oxidative stress. Nat. Rev. Drug Discovery 2004, 3, 205214

(27) LaFerla, F. M. Calcium dyshomeostasis and intracellular signalling in alzheimer's disease. Nat. Rev. Neurosci. 2002, 3, 862-872.

(28) Ghavami, S.; Shojaeid, S.; Yeganeh, B.; Ande, S. R.; Jangamreddy, J. R.; Mehrpour, M.; Christoffersson, J.; Chaabane, W.; Moghadam, A. R.; Kashani, H. H.; Hashemi, M.; Owji, A. A.; Los, M. J. Autophagy and apoptosis dysfunction in neurodegenerative disorders. Prog. Neurobiol. 2014, 112, 24-49.

(29) Nixon, R. A. The role of autophagy in neurodegenerative disease. Nat. Med. 2013, 19, 983-997.

(30) Boland, B.; Kumar, A.; Lee, S.; Platt, F. M.; Wegiel, J.; Yu, W. H.; Nixon, R. A. Autophagy induction and autophagosome clearance in neurons: Relationship to autophagic pathology in Alzheimer's disease. J. Neurosci. 2008, 28, 6926-6937.

(31) Narita, M.; Young, A. R. J.; Arakawa, S.; Samarajiwa, S. A.; Nakashima, T.; Yoshida, S.; Hong, S.; Berry, L. S.; Reichelt, S.; Ferreira, M.; Tavare, S.; Inoki, K.; Shimizu, S.; Narita, M. Spatial Coupling of mTOR and Autophagy Augments Secretory Phenotypes. Science 2011, 332, 966-970.

(32) Sun, Q.; Fan, W.; Chen, K.; Ding, X.; Chen, S.; Zhong, Q. Identification of Barkor as a mammalian autophagy-specific factor for Beclin 1 and class III phosphatidylinositol 3-kinase. Proc. Natl. Acad. Sci. U.S.A. 2008, 105, 19211-19216. 